\title{
Cardiopulmonary response to dynamic exercise after heart and combined heart-lung transplantation
}

\author{
NICHOLAS R BANNER, ${ }^{\dagger}$ MHUGH LLOYD*, RUSSELL D HAMILTON, $\dagger$ \\ J ALASTAIR INNES, $\dagger$ ABRAHAM GUZ, $\dagger$ MAGDI H YACOUB * \\ From the ${ }^{\star}$ Cardiothoracic Unit, Harefield Hospital, Harefield, Middlesex and $\dagger$ Department of Medicine, \\ Charing Cross and Westminster Medical School, London
}

SUMMARY The exercise capacity and cardiopulmonary response to progressive dynamic exercise of eight healthy recipients of heart-lung transplants were compared with those of matched recipients of orthotopic cardiac transplants and normal controls. In both transplant groups the maximum workloads were lower than that in the normal group. The transplant recipients had higher pre-exercise heart rates and lower maximum heart rates than the normal controls. Ventilation during submaximal exercise was similar in the heart transplant group and the controls. The heart-lung group had an increased ventilatory response associated with lower end tidal carbon dioxide concentrations.

Exercise capacity after combined heart-lung transplantation is similar to that after cardiac transplantation. Transplant recipients have an abnormal heart rate response during exercise related to cardiac denervation. The altered ventilatory response in heart-lung recipients may be the result of pulmonary denervation.

Combined heart-lung transplantation is a therapeutic option for patients with end stage pulmonary vascular disease ${ }^{1}$ and parenchymal lung disease. ${ }^{2}$ Successful transplantation can relieve symptoms and improve the patient's quality of life. ${ }^{3}$ However, exercise capacity after transplantation is below predicted values ${ }^{4}$ and the physiological consequences of this extensive operation have not been fully evaluated.

We compared the exercise capacity and cardiopulmonary response to exercise of a group of healthy recipients of heart-lung transplants with that of cardiac transplant recipients and normal controls.

\section{Patients and methods}

We studied eight recipients of heart-lung transplants who were free of cardiopulmonary complications (with the exception of treated hypertension). They were compared with eight normal individuals and eight recipients of cardiac transplants who were matched as closely as possible for age and sex. The transplant recipients were also matched for time after

Requests for reprints to Dr Nicholas $R$ Banner, Cardiothoracic Unit, Harefield Hospital, Harefield, Middlesex UB9 6JH.

Accepted for publication 13 September 1988 operation. Table 1 shows the characteristics of the three groups; predicted values for lung function tests, calculated for the anthropometric characteristics of the subjects, were obtained from Quanjer. ${ }^{5}$ All the transplant recipients were well at the time of the study with no clinical evidence of rejection of the heart or lungs. All had clear chest radiographs and stable lung function tests. None had evidence of cardiac rejection on the most recent endomyocardial biopsy specimen. Table 1 shows the drug treatment in the transplant recipients.

The normal controls were well, had no symptoms or previous history of cardiopulmonary disease, and were not receiving any drug treatment. People who undertook regular exercise training were excluded. The study protocol was approved by the District ethics committee and informed consent was obtained from all subjects.

\section{METHODS}

Exercise tests were performed on an electronically braked cycle ergometer (Lode, Groningen, the Netherlands). The subjects were kept at rest, seated on the exercise bike, for five minutes before data collection started. The study consisted of two minutes' data collection at rest followed by a period of exercise in which the workload was increased by $10 \mathrm{~W}$ every 
Table 1 Characteristics of study groups

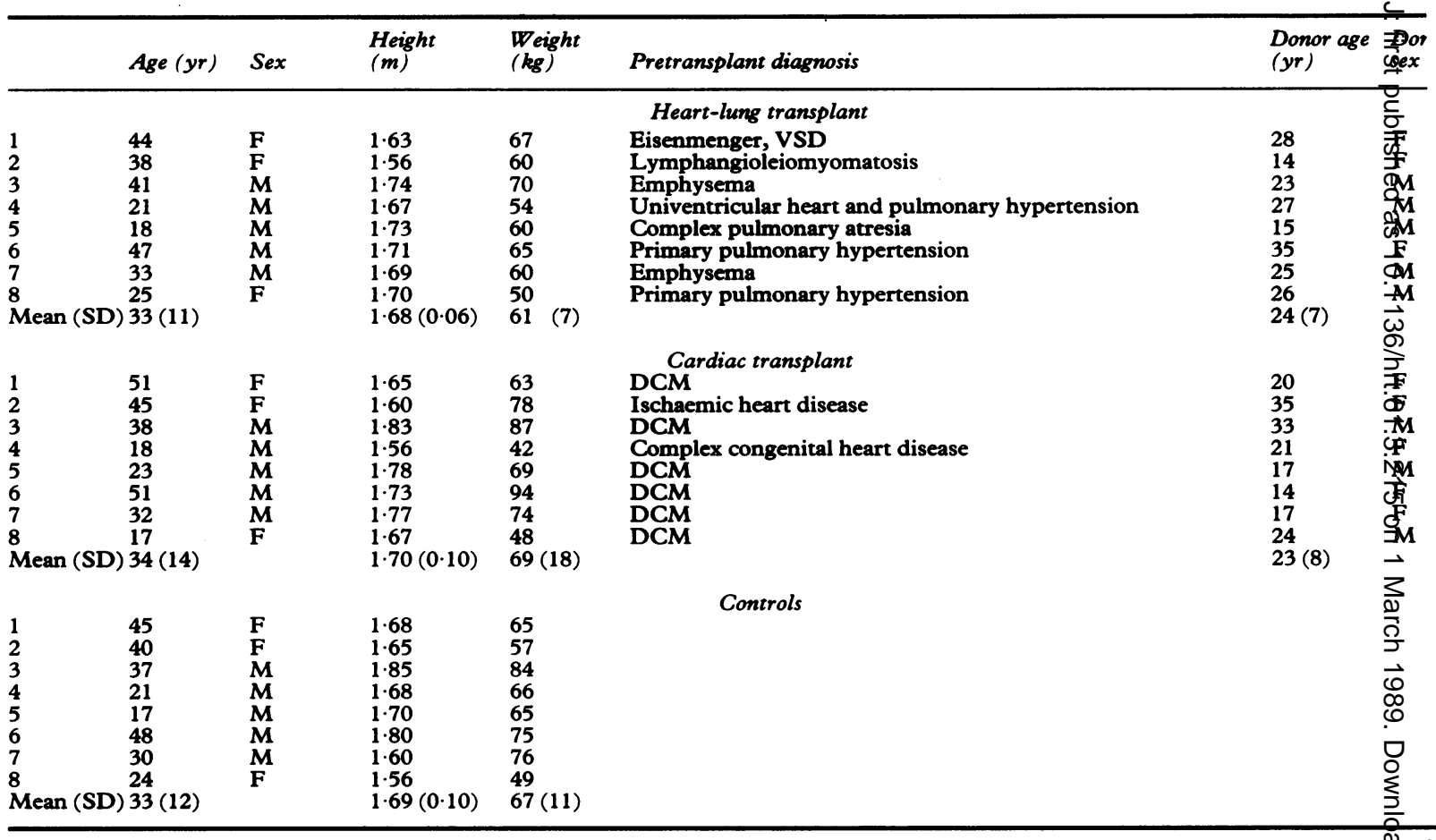

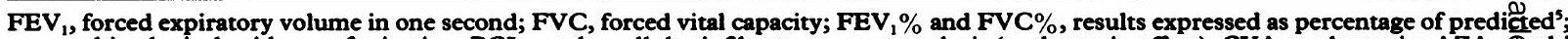
neg, no histological evidence of rejection; PCI, patchy cellular infiltrate, no myocytolysis (cyclosporin effect); CYA, cyclosporin; AZA, dathi ASA, aspirin; DYP, dipyridamole; PRED, prednisone; NFD, nifedipine; HYD, hydralazine; MDP, methyldopa; DCM, dilated cardiọmy VSD, ventricular septal defect.

minute until symptom limited maximum exercise. The subjects breathed via a mouthpiece through a Hans Rudolph valve box (Hans Rudolph, Kansas City, USA). Tidal volume, respiratory frequency, and minute ventilation were measured by a turbine ventilation monitor (PK Morgan, Rainham, UK). Mixed expired oxygen and carbon dioxide concentrations were measured by sampling from a mixing chamber by a computer assisted mass spectrometer (Spectralab “M", VG Medical, Middlewich, UK) and used to calculate oxygen consumption and carbon dioxide production. ${ }^{6}$ End tidal carbon dioxide concentrations were measured at the mouth with a catheter probe connected to the mass spectrometer. The presence of a plateau in the expiratory carbon dioxide tracing was confirmed by a chart recorder; the shape of the tracings was similar in the three groups. Arterial oxygen saturation was recorded continuously with a ear oximeter (Biox III Pulse Oximeter, Ohmeda, Harlow, UK).

Blood pressure was recorded with a sphygmomanometer. Twelve lead electrocardiograms were recorded on a Marquette MAC I exercise electrocardiograph system (Marquette, Manchester, UK), which was also used to measure heart rate. Aver安e values for heart rate and each respiratory variable were measured for each minute. Blood pressure ahd 12 lead electrocardiograms were recorded at rest añd at the end of each three minutes of exercise. The subjects quantified their sensation of breathlessness at the end of each minute on a visual analogue scale. A hand controlled linear potentiometer, mounted iñ a convenient position on the handlebars, allowed the patients to indicate their degree of breathlessness moving a light along a $10 \mathrm{~cm}$ linear display, the ends of which were marked "not at all breathless" afjd "extremely breathless". At the end of the test each person was asked to report the symptoms limitipg their exercise capacity.

STATISTICAL ANALYSIS

ర్

The baseline characteristics of the three groups we compared by analysis of variance. The results are given as mean (SD). Statistical analysis was perfofmed by Student's $t$ test for unpaired data and two way analysis of variance. The level of significance was taken as p $<0.05$ in a two tailed test. Graphs showiRg the data subjected to analysis of variance inclugle 


\begin{tabular}{|c|c|c|c|c|c|c|}
\hline$F E V_{1}(l)$ & $F E V_{1} \%$ & $F V C(l)$ & $F V C \%$ & $\begin{array}{l}\text { Time after } \\
\text { operation (days) }\end{array}$ & Biopsy & Drug treatment \\
\hline \multicolumn{7}{|c|}{ Heart-lung transplant } \\
\hline $\begin{array}{l}28 \\
43 \\
94 \\
22 \\
87 \\
70 \\
54 \\
55 \\
59(0 \cdot 76)\end{array}$ & $\begin{array}{l}121 \\
93 \\
104 \\
104 \\
87 \\
106 \\
121 \\
76 \\
102(16)\end{array}$ & $\begin{array}{l}3 \cdot 71 \\
2 \cdot 75 \\
4 \cdot 21 \\
4 \cdot 59 \\
4 \cdot 3 \\
4 \cdot 28 \\
5 \cdot 18 \\
3 \cdot 08 \\
4 \cdot 01(0 \cdot 80)\end{array}$ & $\begin{array}{r}118 \\
91 \\
91 \\
98 \\
84 \\
100 \\
114 \\
77 \\
97(14)\end{array}$ & $\begin{array}{l}319 \\
364 \\
723 \\
449 \\
372 \\
366 \\
372 \\
119 \\
385(167)\end{array}$ & $\begin{array}{l}\text { Neg } \\
\text { Neg } \\
\text { Neg } \\
\text { Neg } \\
\text { Neg } \\
\text { Neg } \\
\text { Neg } \\
\text { Neg }\end{array}$ & $\begin{array}{l}\text { CYA, AZA, ASA } \\
\text { CYA, AZA, ASA, DYP, NFD } \\
\text { CYA, AZA, DYP, HYD } \\
\text { CYA, AZA, ASA, DYP } \\
\text { CYA, ASA, AZA } \\
\text { CYA, AZA, ASA, DYP } \\
\text { CYA, AZA, ASA, DYP } \\
\text { CYA, AZA, ASA, DYP }\end{array}$ \\
\hline $\begin{array}{l}44 \\
46 \\
26 \\
74 \\
99 \\
71 \\
37 \\
18 \\
26(0 \cdot 98)\end{array}$ & $\begin{array}{r}99 \\
99 \\
100 \\
75 \\
89 \\
107 \\
104 \\
62 \\
92(16)\end{array}$ & $\begin{array}{l}3.14 \\
2.95 \\
5 \cdot 15 \\
3.00 \\
4.57 \\
4.67 \\
5.51 \\
2 \cdot 27 \\
3.91(1 \cdot 20)\end{array}$ & $\begin{array}{r}109 \\
98 \\
99 \\
72 \\
86 \\
109 \\
110 \\
56 \\
92(20)\end{array}$ & $\begin{array}{l}\text { Cardiac transplant } \\
359 \\
261 \\
286 \\
251 \\
356 \\
604 \\
364 \\
155 \\
330(132)\end{array}$ & $\begin{array}{l}\text { Neg } \\
\text { Neg } \\
\text { Neg } \\
\text { Neg } \\
\text { Neg } \\
\text { Neg } \\
\text { PCI } \\
\text { Neg }\end{array}$ & $\begin{array}{l}\text { CYA, AZA, NFD } \\
\text { CYA, AZA, ASA, PRED } \\
\text { CYA, AZA, NFD } \\
\text { CYA, AZA, ASA, DYP, PRED } \\
\text { CYA, AZA, ASA, DYP, MDP, HYD } \\
\text { CYA, AZA } \\
\text { CYA, AZA, ASA, DYP, HYD } \\
\text { CYA, AZA, ASA, DYP }\end{array}$ \\
\hline \multicolumn{7}{|c|}{ Controls } \\
\hline $\begin{array}{l}73 \\
44 \\
92 \\
84 \\
77 \\
87 \\
77 \\
41 \\
59(0 \cdot 40)\end{array}$ & $\begin{array}{r}94 \\
118 \\
89 \\
93 \\
87 \\
100 \\
107 \\
115 \\
100(12)\end{array}$ & $\begin{array}{l}3 \cdot 77 \\
4 \cdot 04 \\
5 \cdot 14 \\
4 \cdot 54 \\
4 \cdot 07 \\
5 \cdot 72 \\
4 \cdot 47 \\
3 \cdot 68 \\
4 \cdot 42(0 \cdot 71)\end{array}$ & $\begin{array}{l}111 \\
120 \\
96 \\
95 \\
81 \\
114 \\
109 \\
108 \\
104(13)\end{array}$ & & & \\
\hline
\end{tabular}

Fisher's least significant difference for comparing observations between groups at the $5 \%$ significance level. ${ }^{8}$ The visual analogue scores at maximum exercise were anlysed non-parametrically by the Mann-Whitney U test.

\section{Results}

There were no significant differences in the baseline characteristics of the three groups (table 1).

\section{BEFORE EXERCISE}

All subjects were in sinus rhythm. The controls had normal electrocardiograms. Three patients with heart-lung transplants had electrocardiograms that were within normal limits; one had complete right bundle branch block and four had $\mathrm{T}$ wave inversion in the anterior chest leads; one of these four also had $T$ wave inversion in the inferior leads and another had left ventricular hypertrophy on voltage criteria $\left(\mathrm{SV}_{2}+\mathrm{RV}_{5}>3.5 \mathrm{mV}\right)$. This subject's blood pressure at rest was $100 / 70 \mathrm{~mm} \mathrm{Hg}$ and he was not receiving antihypertensive treatment. Five of the cardiac transplant recipients had electrocardiograms within normal limits; one had partial right bundle branch block and two had $\mathrm{T}$ wave inversion in the anterior chest leads.

\section{MAXIMUM EXERCISE}

All subjects were exercised to their symptom limited maximum and no adverse reactions occurred during the test. Table 2 shows the symptoms limiting exercise capacity. Figure 1 shows the maximum level of exercise achieved in the three groups as indicated by workload and oxygen consumption in both transplant groups. The maximum workload was lower than in the normal controls $(p<0.01)$. There was no significant difference between the maximum workload achieved between the cardiac transplant recipients and the heart-lung recipients. Peak oxygen uptake was lower in both transplant groups but the difference only reached statistical significance for the heart-lung group ( $p<0.05$ ). Peak oxygen uptake in relation to body weight was also lower in the transplant groups: normal controls 30 (4) $\mathrm{ml} / \mathrm{kg}$; heartlung recipients $22(7) \mathrm{ml} / \mathrm{kg}(\mathrm{p}<0.05)$, and heart transplant recipients $23(10) \mathrm{ml} / \mathrm{kg}(\mathrm{p}=\mathrm{NS})$. The normal controls achieved higher maximum heart 

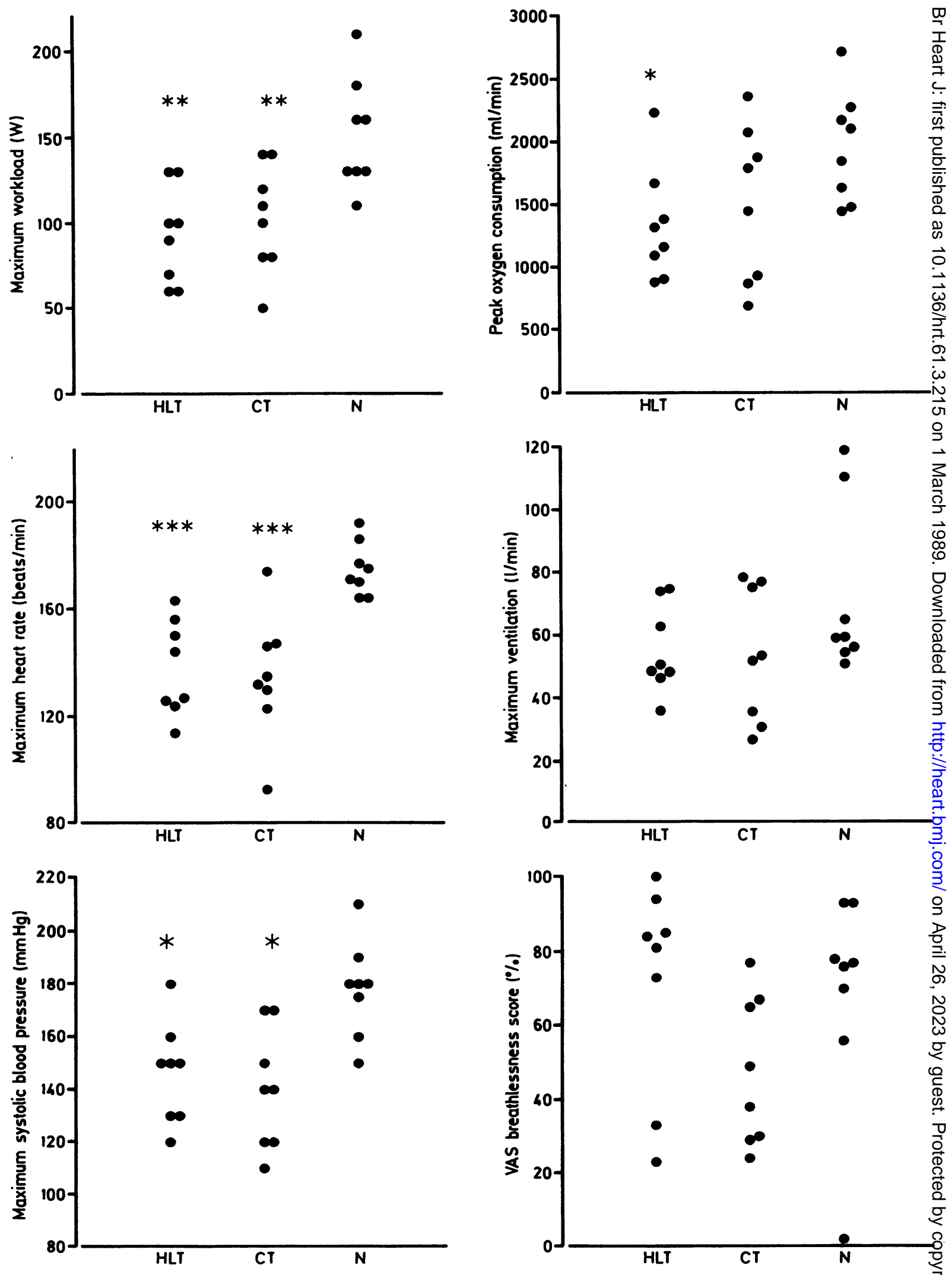

Fig 1 Maximum exercise response in heart-lung transplant recipients (HLT); orthotopic cardiac transplant recipients $\stackrel{\bar{Q}}{\text { ( }}$ $(C T)$; normal controls $(N) .{ }^{\star} p<0.05 ;{ }^{\star \star} p<0.01 ;{ }^{\star \star \star} p<0.001$ for unpaired $t$ tests (comparison with normal controls) $V A S$, visual analogue scale. 
Table 2 Symptoms limiting exercise capacity during test

\begin{tabular}{llll}
\hline & $\begin{array}{l}\text { Heart-lung } \\
\text { transplant }\end{array}$ & $\begin{array}{l}\text { Cardiac } \\
\text { transplant }\end{array}$ & Normal \\
\hline Fatigue & 2 & 6 & 6 \\
Dyspnoea & 2 & 1 & 1 \\
Both & 4 & 1 & 1 \\
\hline
\end{tabular}

rates than either of the transplant groups $(p<0.001)$.

There was no significant difference in maximum ventilation. Maximum systolic blood pressure was higher in the normal subjects than in either transplant group ( $p<0.05)$. There was no significant difference in breathlessness at maximum exercise, as measured by the visual analogue scale, between the normal subjects and either transplant group (MannWhitney U test).

\section{PATTERN OF EXERCISE RESPONSE}

We examined the differences in the incremental response to exercise in the three groups by a two way analysis of variance. Because this approach required an equal number of data points in each group, the response could be analysed only up to the maximum workload achieved by all subjects ( $50 \mathrm{~W}$ ) (fig 2 ).

\section{Cardiovascular response}

All subjects remained in sinus rhythm throughout the test and no significant electrocardiographic changes occurred during exercise. At rest the heart rates of both transplant groups were significantly greater than that in the normal controls $(p<0.01)$. During exercise there were no significant differences in heart rates at workloads where analysis of variance could be performed. To determine the workload at which the heart rate was significantly increased from the resting level, we used Fisher's least significant difference for observations within a group (for $p<0.05$ ). ${ }^{8}$ In the normal subjects this occurred at the first stage of exercise $(10 \mathrm{~W})$ whereas in both transplant groups it did not occur until the $30 \mathrm{~W}$ stage (that is the response was delayed by two minutes). There was no significant electrocardiographic changes during exercise in any subject.

Figure 2 shows the blood pressure response of the three groups. There were no significant differences in systolic blood pressure between the three groups at rest, 30, or $60 \mathrm{~W}$ (one cardiac transplant recipient did not reach the $60 \mathrm{~W}$ stage and the blood pressure at 50 W was used for analysis of variance). Systolic blood pressure rose significantly on exercise in all three groups $(p<0.001)$. Heart-lung recipients tended to have slightly lower diastolic pressures and this difference was just significant at the $30 \mathrm{~W}$ stage. There was no significant change in diastolic blood pressure in any group during exercise.

\section{Respiratory response}

Before exercise the heart-lung transplant group tended to have higher values for ventilation, oxygen uptake, and carbon dioxide production; however, the difference was statistically significant only for carbon dioxide production during the first minute. During exercise there was no significant difference in oxygen consumption or carbon dioxide production among the three groups. Ventilation was greater in the heart-lung transplant recipients than in the normal controls and this was statistically significant at and above the $30 \mathrm{~W}$ stage. Ventilation in the cardiac transplant patients was, in general, higher than that in the normal controls but this difference was only significant at the $30 \mathrm{~W}$ stage. The increase in ventilation in the heart-lung transplant patients was achieved by an increase in both tidal volume and respiratory rate while that in the cardiac transplant patients was achieved by an increase in respiratory rate alone.

The oxygen consumption corresponding to the anaerobic threshold for each subject was estimated from the point where ventilation began to increase non-linearly with oxygen uptake. ${ }^{9}$ For the normal subjects this was $1.43(0.38) 1 /$ min oxygen; for the heart-lung group it was $1.0(0.32) 1 / \mathrm{min}(\mathrm{p}=\mathrm{NS})$, and for the cardiac transplant group it was $1.2(0.46)$ $1 / \min (p=N S)$. The ventilatory equivalent for oxygen in each person was obtained from the slope of the linear regression line of ventilation against oxygen uptake below the anaerobic threshold. ${ }^{10}$ The mean slope for the normal controls was $23.9(5.5)$; for the heart-lung group it was $30.8(6 \cdot 1)(p<0.05)$, and for the cardiac transplant group it was $25 \cdot 8(3 \cdot 2)$ ( $p=$ NS). The ventilatory equivalent for carbon dioxide was obtained in a similar manner. The mean slope for the normal controls was 23.5 (3.2); for the heart-lung group it was $30.5(4.7)(p<0.01)$, and for the cardiac transplant group it was $27 \cdot 1(3 \cdot 8)(p=N S)$.

Oxygen saturations were similar for all three groups. The end tidal carbon dioxide value was significantly lower in the heart-lung recipients than in the normal $(\mathrm{p}<0.02)$ and cardiac transplant $(\mathrm{p}<$ 0.02 ) groups.

\section{Discussion}

Combined heart-lung transplantation can alleviate symptoms and improve the quality of life of patients with severe pulmonary vascular disease and parenchymal lung disease. ${ }^{3}$ We have been impressed by the excellent degree of rehabilitation achieved by most heart-lung transplant recipients. In some patients, however, long term complications develop (especially chronic airflow obstruction in the transplanted lung ${ }^{11}$ ), and the physiological consequences 

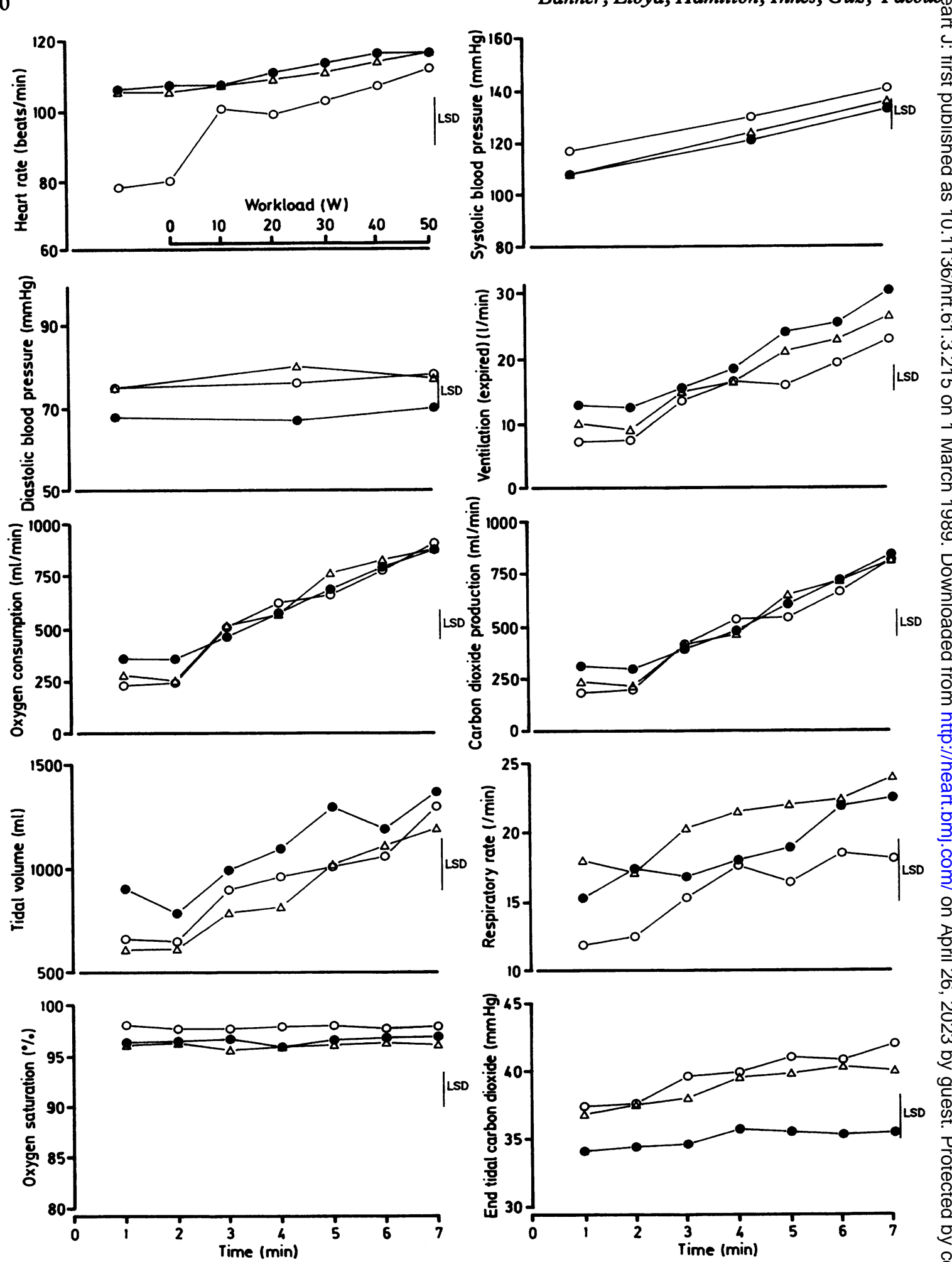

Fig 2 Evolution of the exercise response in heart-lung transplant recipients ( $)$ ), cardiac transplant recipients $(\triangle)$, and normal controls (O). LSD, Fisher's least significant difference for observations between groups $(p<0.05)$. 
of the procedure have not been fully defined. This study was designed to compare the exercise capacity and pattern of exercise response of a group of healthy heart-lung transplant recipients with those of cardiac transplant recipients and normal controls. We selected transplant recipients who had no serious complications after transplantation.

Our results confirm the findings of a previous study which showed that recipients of heart-lung transplants had an exercise capacity that was less than that predicted for normal controls. ${ }^{4}$ In addition, we have established that their exercise capacity is similar to that of matched cardiac transplant recipients. The reduced exercise capacity of patients with orthotopic cardiac transplants has already been shown. ${ }^{12} 13$ Several factors may contribute to the reduced exercise capacity after heart and heart-lung transplantation.

Illness before transplantation will have produced a period of deconditioning and muscle wasting that may persist after operation. A recent study showed a delayed recovery in the vasodilator response of skeletal muscle after cardiac transplantation. This may reflect a persistent effect of preoperative cardiac failure and deconditioning, which could affect exercise capacity. ${ }^{14} \mathrm{~A}$ previous study of cardiac transplant recipients at our hospital found them to have a reduced lean body mass and exercise capacity compared with normal controls. A programme of regular exercise training improved exercise capacity and increased lean body mass although their exercise capacity was still less than that of controls. ${ }^{13}$

There is the possibility of residual left ventricular dysfunction related to the process of brain death in the donor, ${ }^{15}$ the organ preservation at the time of transplantation, and subsequent episodes of cardiac rejection. We found that the systolic ventricular function of cardiac transplant recipients treated with cyclosporin was, however, usually normal. ${ }^{16}$

The heart-lung transplant operation ${ }^{17}$ has several physiological consequences. The heart and lungs are transplanted as a single block replacing the recipient's diseased organs. Vascular anastomoses are made between the donor right atrium and a remnant of the recipient's right atrium and between donor and recipient ascending aorta (the donor left atrium remains intact). The tracheal anastomosis is made between the lower part of the recipient's trachea and the donor trachea just above the carina. The procedure results in acute denervation of the transplanted heart and lungs. The recipient retains tracheal innervation down to the level of this anastomosis and the recurrent laryngeal nerves remain intact. The pulmonary lymphatic system and bronchial circulation are sacrificed.

Orthotopic cardiac transplantation results in com- plete denervation of the transplanted heart but the pulmonary innervation, lymphatic system, and the bronchial circulation are not affected. Cardiac reinnervation has not been seen in patients after orthotopic cardiac transplantation ${ }^{18}$ although evidence of efferent reinnervation has been found in recipients at heterotopic transplants. ${ }^{19}$ In dogs cardiac and pulmonary reinnervation can occur after transplantation of the heart ${ }^{20}$ or lung. ${ }^{21}$ The sinus tachycardia before exercise together with the identical, abnormal, heart rate response during exercise of the heart-lung and heart transplant recipients studied here provide evidence of persistent cardiac denervation. It has been difficult to show pulmonary denervation in heart-lung transplant recipients non-invasively because of the presence of an innervated trachea. Recipients of heart-lung transplants do not have an increased cough threshold when tested with a citric acid aerosol (Banner N R et al, unpublished). They do, however, have increased airways responsiveness to methacholine. This may represent a denervation hypersensitivity of muscarinic receptors in the airways of the transplanted lung. ${ }^{22} 23$

The difference in exercise capacity between the transplant groups and normal individuals was not caused by altered mechanical or metabolic efficiency as the relation of oxygen consumption and carbon dioxide production to workload was the same in all three groups. Because the two transplant groups showed a similar performance the overall limitation is likely to be related to the circulation and the transplanted heart rather than to the transplanted lungs. This view is supported by the ventilatory response, which provided indirect evidence of anaerobic metabolism developing during exercise in all three groups in this study, and the increased lactate concentrations found in recipients of heartlung transplants at maximum exercise in another study. ${ }^{4}$

The abnormal response of heart rate to exercise may contribute to the reduced exercise capacity of the transplant recipient. The increased resting heart rate in the transplant recipients is caused by a loss of vagal tone. ${ }^{18}$ The delayed response of heart rate at the start of exercise is associate with an impaired initial cardiac output response. ${ }^{24}$ All three groups, however, had similar heart rates during the first few minutes of exercise in this study. The lower peak heart rates achieved by the transplant recipients might limit maximum cardiac output or they may just reflect the lower workloads reached by the transplant recipients. The cardiac output of heart transplant recipients (measured under steady state conditions during submaximal exercise) is normal in relation to oxygen uptake. ${ }^{25}$ The slow response of heart rate may place the transplant patient at a particular disadvan- 
tage during an incremental exercise test. A previous study found that the cardiac output response of recipients of heart transplants to exercise was caused by a prominent rise in stroke volume and a slow rise in heart rate; because cardiac output was low in relation to oxygen uptake there was an increase in the arteriovenous oxygen difference ${ }^{26}$ Exercise training improves the response of heart rate to exercise in cardiac transplant recipients and the improvement is associated with an increased exercise capacity. ${ }^{13}$ Cardiac denervation may affect cardiac function in other ways. Contractility and the contractile reserve of the left ventricle in the transplanted heart seem normal when tested pharmacologically ${ }^{27}$ but the effects of chronic cardiac denervation on left ventricular performance during exercise are unknown.

Hypertension is a common complication of cyclosporin treatment in heart transplant recipients. ${ }^{28} 29$ Four heart and two heart-lung recipients in this study were on antihypertensive treatment. The systolic blood pressure response to exercise was similar in all three groups.

Cardiac transplant recipients have been reported to have increased ventilation in relation to oxygen uptake during exercise. ${ }^{12}$ The cardiac transplant group in the present study had a slightly increased ventilation compared with the normal controls but the difference was not statistically significant. Analysis by linear regression of ventilation against oxygen uptake shows that the response was close to the published values for a similar exercise protocol. ${ }^{10}$ The end tidal carbon dioxide concentrations were normal in the cardiac transplant group, confirming that alveolar ventilation was normal. The relatively normal ventilatory response in these patients may be because of the improvement in ventricular function that we saw in cardiac transplant recipients treated with cyclosporin compared with conventional immunosuppression. ${ }^{16}$ In addition, the ventilatory response of cardiac transplant recipients is related to their physical fitness and can be altered by exercise training. ${ }^{13}$

In contrast, both analysis of variance at equivalent workloads or by linear regression of ventilation against oxygen below the anaerobic threshold showed an increased ventilatory response in the heart-lung group; this was owing to a combination of increased respiratory rate and tidal volume. A case of increased ventilation during exercise in a heart-lung transplant recipient was reported while the present work was in progress. ${ }^{30}$

The increased ventilatory response in our study did not seem to be the result of poor pulmonary gas exchange. Oximetry showed that the heart-lung group did not desaturate during exercise and end tidal carbon dioxide concentrations were low, sug-
Banner, Lloyd, Hamilton, Innes, Guz, Yaco伢

gesting that true alveolar hyperventilation was occu诖ring. It may be that the increased ventilation and low end tidal carbon dioxide concentrations were the result of regions of high ventilation and low perfusign in the transplanted lungs. The heart-lung group ha्gd good baseline lung function, however, which males this explanation unlikely. Another study found lo arterial carbon dioxide tensions in heart-lung transplant recipients before and during exercise although it did not compare them with those in normal controls. ${ }^{4}$ The alveolar hyperventilation might be caused by the sluggish heart rate response with the early development of a lactic acidosis during exercise. The small increase in ventilation seen in the cardiac transplant group who had a similar exercise capacity and cardiovascular response to exercise does not support this idea. Drug treatment was similar in the two transplant groups so the increased ventilationgis not the result of medication.

The mechanisms controlling exercise hyperpno are complex and poorly understood. Most of the attention in this area has been focused on mechanisms stimulating ventilation rather than those resstraining it. ${ }^{31}$ Our results suggest that an increased ventilatory response to exercise occurs after pulmouary denervation, but not after cardiac denervatio We found that the ventilatory response to carbon dioxide was increased in heart-lung transplamt recipients. $^{32}$ A possible explanation is that the increased ventilatory response to these stimuli is caused by the loss of negative feedback from pulmo ary afferents in the heart-lung recipients.

The heart-lung recipients were still able to perceive breathlessness during exercise and the maximum breathlessness scores were similar in the three groups. This indicates that pulmonary afferents not make an essential contribution to the sensation $\bar{g} f$ exertional dyspnoea.

In conclusion, heart-lung and heart transplaĥ recipients have a similar exercise capacity and cardiovascular response to exercise. The altered cardiovascular response is partly the result of carditc denervation and their exercise capacity seemed to Be limited by circulatory performance. The heart-luef transplant recipients also show an increased veptilatory response during submaximal exercise, whißh may be caused by a loss of negative feedback from the pulmonary afferents. Exercise capacity after hear lung transplantation is sufficient for everydey activities and transplantation can provide excelle rehabilitation of patients with end stage cardioputmonary disease.

We thank Dr Ken MacRae for statistical advice. 


\section{References}

1 Reitz BA, Wallwork JL, Hunt SA, et al. Heart lung transplantation: successful therapy for patients with pulmonary vascular disease. $N$ Engl $J$ Med 1982;306:557-64.

2 Penketh A, Higenbottam T, Hakim M, Wallwork J. Heart-lung transplantation in patients with end stage lung disease. $\mathrm{Br}$ Med J 1987;295:311-4.

3 Yacoub MH, Banner NR, Gibson S, Thakrar SA, Khaghani A. A quantitative assessment of the quality of life after combined heart-lung transplantation [Abstract]. J Am Coll Cardiol 1987;9:30A.

4 Theodore J, Morris AJ, Burke CM, et al. Cardiopulmonary function at maximal tolerable constant work rate exercise following human heart-lung transplantation. Chest 1987;92:433-9.

5 Quanjer $\mathrm{Ph} \mathrm{H}$, ed. Standardized lung function testing. Bull Eur Physiopath Resp 1983;19 (suppl 5):45-51.

6 Jones NL, Campbell EJM. Clinical exercise testing. Philadelphia, WB Saunders, 1982:231-9.

7 Adams L, Chronos N, Lane R, Guz A. The measurement of breathlessness in normal subjects: validity of two scaling techniques. Clin Sci 1985;69: 7-16.

8 Fisher RA. The design of experiments. Edinburgh: Oliver and Boyd, 1935.

9 Wasserman K, Whipp BJ, Koyal SN, Beaver WL. Anaerobic threshold and respiratory gas exchange during exercise. J Appl Physiol 1973;35:236-43.

10 Spiro SG, Juniper E, Bowman P, Edwards RHT. An increasing work rate test for assessing the physiological strain of submaximal exercise. Clin Sci 1974;46:191-206.

11 Burke CM, Theodore J, Dawkins KD, et al. Post transplant obliterative bronchiolitis and other late lung sequelae in human heart-lung transplantation. Chest 1984;86:824-9.

12 Savin WM, Haskell WL, Schroeder JS, Stinson EB. Cardiorespiratory responses of cardiac transplant patients to graded, symptom limited exercise. Circulation 1980;62:55-60.

13 Kavanagh T, Yacoub MH, Mertens DJ, Kennedy J, Campbell RB, Sawyer P. Cardiorespiratory responses to exercise training after orthotopic transplantation. Circulation 1988;77:162-71.

14 Sinoway LI, Minotti JR, Davis D, et al. Delayed reversal of impaired vasodilation in congestive heart failure after heart transplantation. Am J Cardiol 1988;61:1076-9.

15 De Pasquale NP, Burch GE. How normal is the donor heart? Am Heart J 1969;77:719-20.

16 Reid CJ, Yacoub MH. Determinants of left ventricular function one year after cardiac transplantation. $\mathrm{Br}$ Heart $J$ 1988;59:397-402.

17 Jamieson SW, Stinson EB, Oyer PE, Baldwin JC, Shumway NE. Operative technique for heart-lung transplantation. J Thorac Cardiovasc Surg 1984; 87:930-5.

18 Horak AR. Physiology and pharmacology of the transplanted heart. In: Cooper DKC, Lanza RP, eds. Heart transplantation. Lancaster: MTP Press, 1984:147-56.

19 Mitchell AG, Yacoub M. Efferent autonomic reinnervation after heterotopic cardiac transplantation in humans [Abstract]. Br Heart J 1987;57:87.

20 Kontos HA, Thames MD, Lower RR. Response to electrical and reflex autonomic stimulation in dogs with cardiac transplantation before and after reinnervation. J Thorac Cardiovasc Surg 1970;59:382-92.

21 Edmunds LH, Graf PD, Nadel JA. Reinnervation of the reimplanted canine lung. J Appl Physiol 1971;31: 722-7.

22 Banner NR, Hollingshead L, Dear I, Heaton R, Guz A, Yacoub $M H$. Increased bronchial reactivity to methacholine following combined heart lung transplantation [Abstract]. Thorax 1987;42:239-40.

23 Glanville AR, Burke CM, Theodore J, et al. Bronchial hyper-responsiveness after human cardiopulmonary transplantation. Clin Sci 1987;73:299-303.

24 Banner NR, Guz A, Heaton R, Innes JA, Murphy K, Yacoub $M$. Ventilatory and circulatory responses at the onset of exercise in man following heart or heartlung transplantation. J Physiol (Lond) 1988;399: 437-49.

25 Mertens D, Kavanagh T, Yacoub $M$. Long term exercise training and cardiac output following cardiac transplantation [Abstract]. J Am Coll Cardiol 1987; 9:235.

26 Stinson EB, Griepp RB, Schroeder JS, Dong E, Shumway NE. Haemodynamic observations one and two years after cardiac transplantation in man. Circulation 1972;45:1183-94.

27 Borow KM, Neumann A, Arensman FW, Yacoub MH. Left ventricular contractility and contractile reserve in humans after cardiac transplantation. Circulation 1985;71:866-72.

28 Goldman MH, Barnhart G, Mohanakumar T, et al. Cyclosporine in cardiac transplantation. Surg Clin $N$ Am 1985;65:637-59.

29 Banner NR, Fitzgerald M, Khaghani A, et al. Cardiac transplantation at Harefield Hospital. In: Terasaki $P$, ed. Clinical transplants 1987. Los Angeles: UCLA Tissue Typing Laboratory, 1987:17-26.

30 Estenne M, Primo G, Yernault JC. Cardiorespiratory responses to exercise after human heart-lung transplantation. Thorax 1987;42:629-30.

31 Whipp BJ. The control of exercise hyperpnea. In Hornbein TF, ed. Regulation of breathing (part 2). New York, Marcel Dekker, 1981:1069-139.

32 Banner NR, Lloyd MH, Lane R, Guz A, Yacoub MH. Ventilatory response to progressive hypercapnic stimulation following combined heart lung transplantation in man [Abstract]. Clin Sci 1977;73 (suppl 17):6P. 